\title{
Effect of Different Category of Geogrid and Sand Layer on Pull-out Behaviour
}

\author{
Mojtaba Firoozi Nezamabadi ${ }^{1}$, S. Hamid Lajevardi ${ }^{1}$, Mehrdad Sadeghi \\ ${ }^{1}$ Department of Civil Engineering, Arak Branch, Islamic Azad University \\ Arak, Iran \\ Firoozi56@gmail.com; sh-lajevardi@iau-arak.ac.ir \\ ${ }^{2}$ Faculty of Shahab Danesh University \\ Qom, Iran \\ sadeghi.mehrdad@gmail.com
}

\begin{abstract}
Geosynthetics are used as reinforcing elements in different soil structure: reinforced slops and walls; embankments on soft soils; reinforcement in the base layers of road construction; bridging of sinkholes or reinforced abutments. The pull-out test is one of the methods that used to study pull-out behaviour and soil-reinforcement interaction .In current study, the pull-out test has been modelled by finite element to investigate possibility of pull-out resistance enhancement of clay reinforced with three categories of geogrid (homogenous, coated woven, welded straps) embedded in thin layers of sand. Pull-out test on sand-geogrid, clay-sand-geogrid samples have been simulated at normal pressure of $50 \mathrm{kPa}$. Numerical results show the provision of thin layers around the geogrid. Significantly increase pull-out resistance of clay soil under monition loading conditions and optimum ratio sand layer thickness to box test height of 0.15 has been determined for maximum enhancement. The pull-out force increase with increasing the axial stiffness (EA) in Welded straps geogrid.
\end{abstract}

Keywords: Geogrid, Numerical study, Pull-out test, Soil reinforcement

\section{Introduction}

It is expected As an important reinforcement material in practice, geogrids have been used in dealing with various geotechnical problems, e.g. stabilizing the soil structures; embankment on soft soil reinforced slops; increasing the bearing capacity (Lajevardi etal.,2013; Lajevardi et al.,2014; Palmeira, 2004; Teixeira et al., 2007; Moraci and Cardile,2009). In all experimental studies, the pull-out test has been regard as a better way to investigate the geogrid-soil interface behaviour (Yogarajah and Yeo, 1994). Plenty of pull-out tests has been carried out based on various geogrid soil types ( e.g Bergado and Chai,1994; Palmeira, 2004; Teixeira et al., 2007; Moraci and Cardile,2009; Palmeira, 2009; Abdi and Arjomand, 2011; Esfandiari and Selamat, 2012; Moraci and Cardile, 2012; Mosallanezhad et al.,2016).

In order to save cost aggregate extraction, there is a tendency to use low quality granular materials have been the preferred backfill material due to their high strength and ability to dissipate excess pore water pressures rapidly (Elias and Christopher, 1996; Abdi and Zandieh, 2014).Many researchers studied various factors affecting pull-out response of reinforcements in sand, such as box size, sleeve length, test speed, soil-geogrid interaction (Bergado et al., 1987; Palmeira and Meilligan,1989; Palmeira, 2009; Abdi and Zandieh, 2014).Only limited number of studies carried out to investigation of Interaction between cohesive soils and geogrid (Bergado et al.,1991; Keller, 1995; Abdi et al., 2009;Rowe and Taechakumthorn, 2011) and Khedkar and Mandal (2009), Abdi and Zandieh (2014) pull-out test have been modelled by finite element of analysis using geotechnical software.

Lack of good quality granular soils or costs of using of inferior low quality clay soils in reinforced soil structures. When clay soils is used in reinforced soil, a thin sand layer around the geogrid will be increased stability, pull-out resistance and promote soil-reinforcement interaction.

The pull-out test will help to study soil-reinforcement interaction and numerical study is complementary in experimental study. 
This study investigates effect of different categories of geogrid on pull-out resistance in clay-sand-geogrid and sandgeogrid samples numerically .pull-out test has been modelled by the finite element software that used to model pull-out test.

\section{Numerical model}

Pull-out simulation has been considered as a plane strain problem where displacements and strains in the direction parallel to the length of the retaining wall or the width of box are assumed equal to zero (Khedkar and Mandal, 2009).

\subsection{Material}

Finite elements Young's modulus as basic stiffness modulus in elastic and Mohre-Coulomb models. The initial slope of stresses- strain curve of sand is usually indicated as E and the secant modulus at $50 \%$ strength is denoted as $\mathrm{E}_{50}$. For highly over-consolidated clays and some rocks, it is realistic to use $\mathrm{E}$, however, for sands it is more appropriate to use $\mathrm{E}_{50}$ .Volumetric changes which occur during shearing of soils can be conveniently characterized by dilatancy angle (Abdi and Zandieh, 2014).

\subsubsection{Reinforcement}

Fig. 1 shows the three categories of geogrids which have been used in this study. Fig. 2(a) illustrates the original type of geogrids, in this category polypropylene square sheets are punched and then is drawn longitudinally. Fig. 2(b) shows coated woven geogrid. In this category used 200 high tenacity polyester filament and contained them in very different compositions. They were fabricated in to grid structure by melt bonding the overlapping sheets together. Fig. 2(c) shows welded straps geogrid made from high tenacity PET or polypropylene (pp) rods or straps. In this type grid structure ultrasonically welded them together with aid of steel screen placed within the intersections (Koerner, 2009). The geometrical and strength characteristics of three categories geogrids are presented in Table. 1.

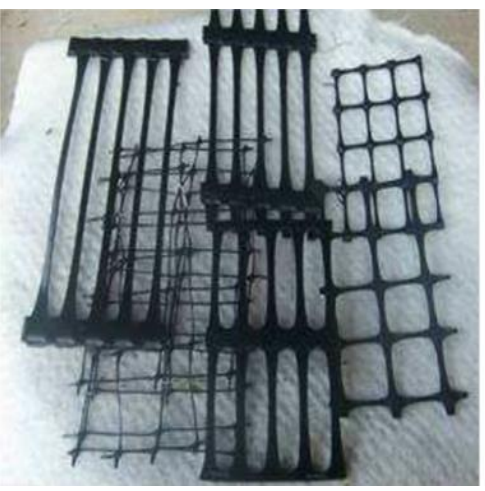

(a)Homogenous (HDPE)

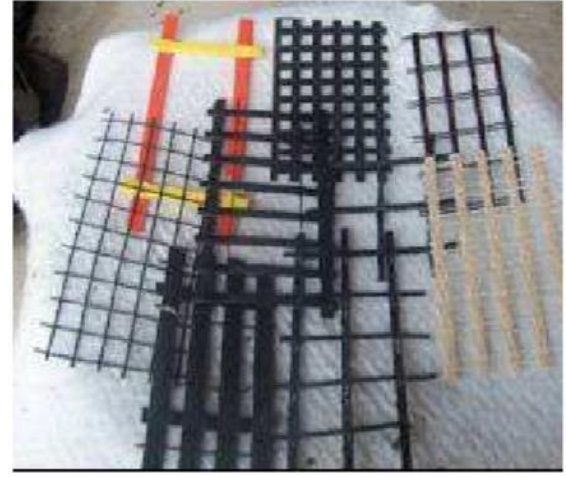

(b) Coated woven

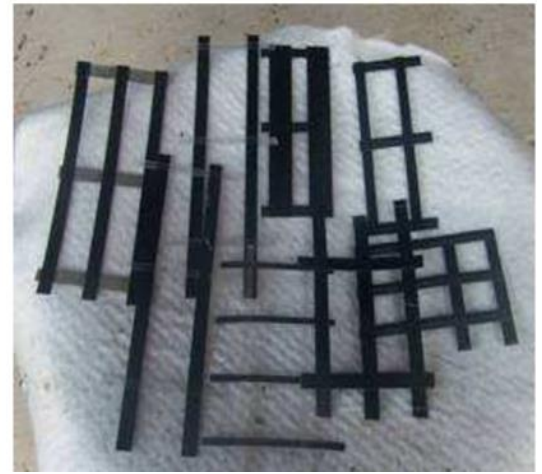

(c) Welded straps

Fig. 1: Three categories of geogrids (Koerner, 2009).

Table 1: Properties of geogrids (Koerner, 2009).

\begin{tabular}{|c|c|c|c|c|c|c|}
\hline \multirow[t]{2}{*}{$\begin{array}{c}\text { Type } \\
\text { Geogrid }\end{array}$} & \multirow{2}{*}{$\begin{array}{c}\text { Maximum } \\
\text { tensile } \\
\text { strength } \\
(\mathrm{KN} / \mathrm{m}) \\
\end{array}$} & \multicolumn{2}{|c|}{$\begin{array}{l}\text { Size mesh } \\
(\mathrm{mm})\end{array}$} & \multirow[t]{2}{*}{$\underset{(\mathrm{mm})}{\mathrm{d}}$} & \multirow[t]{2}{*}{$\begin{array}{c}\text { EA } \\
(\mathrm{kN} / \mathrm{m})\end{array}$} & \multirow[t]{2}{*}{$\begin{array}{c}\text { Material } \\
\text { type }\end{array}$} \\
\hline & & MD & $\mathrm{CD}$ & & & \\
\hline Homogenous(HDPE) & 90 & 200 & 15 & 15 & 1020 & elastic \\
\hline Coated woven & 80 & 20 & 35 & 2 & 950 & elastic \\
\hline Welded straps & 80 & 73 & 30 & 7 & 1120 & elastic \\
\hline
\end{tabular}

$\mathrm{MD}=$ machine direction, $\mathrm{CD}=$ cross machine direction, $\mathrm{d}=$ equivalent depth

\subsubsection{Soil material}

A fine grained soil and granular material have been used, cohesive and granular soils were selected kaolinite and natural sand respectively. The parameters that used for numerical model are presented in Table. 2 . Their physical 
properties determined according to ASTM Standards. Fig. 2 illustrates particle size distribution curves of clay and sand.

Table 2: Properties of soils (Abdi and Zandieh, 2014).

\begin{tabular}{|l|l|l|l|l|l|l|l|l|}
\hline soil & $\begin{array}{c}\text { Maximum } \\
\text { dry } \\
\text { density } \\
\left(\mathrm{Kn} / \mathrm{m}^{3}\right)\end{array}$ & $\begin{array}{c}\text { Elasticity } \\
\text { modulus } \\
(\mathrm{E}) \\
\left(\mathrm{Kn} / \mathrm{m}^{2}\right)\end{array}$ & $\begin{array}{c}\text { Cohesion } \\
(\mathrm{c}) \\
\left(\mathrm{Kn} / \mathrm{m}^{2}\right)\end{array}$ & $\begin{array}{c}\text { Dilation } \\
\text { angle }\end{array}$ & $\begin{array}{c}\text { Angle } \\
\text { of } \\
\text { friction }\end{array}$ & $\begin{array}{c}\text { Poisson's } \\
\text { ratio }\end{array}$ & $\begin{array}{c}\text { Interaction } \\
\text { coefficient } \\
\text { for } \\
\text { transverse } \\
\text { member } \\
\left(\mathrm{R}_{\text {inter }}\right)\end{array}$ & $\begin{array}{c}\text { Material } \\
\text { model }\end{array}$ \\
\hline Sand & 17 & 38000 & 0.01 & 8 & 21 & 0.31 & 0.17 & Mohr-coulomb \\
\hline clay & 15.7 & 9000 & 23 & 0 & 38 & 0.38 & 0.11 & Mohr -coulomb \\
\hline
\end{tabular}

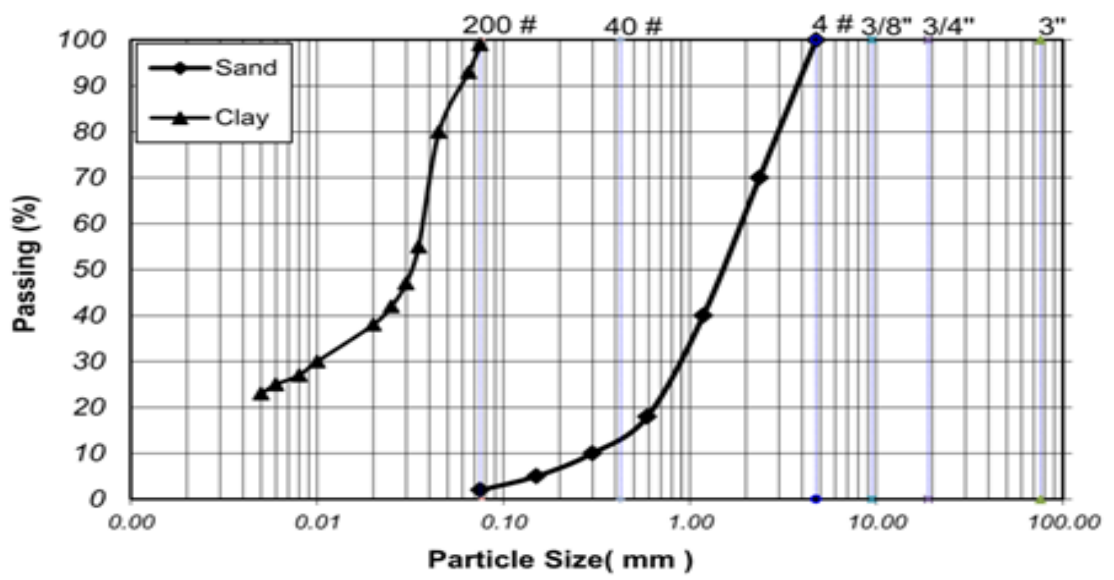

Fig. 2: Particle size distribution curves of clay and sand (Abdi and Zandieh, 2014).

\subsubsection{Geo-foam}

To reduce rigidity effects of frontal face of the box, a $1.0 \mathrm{~cm}$ thickness geo-foam sheet was placed on inner face of the front wall.(Sugimoto et al,2001;Abdi and Zandieh,2014).The geo-foam parameters used for finite elements software are presented in Table. 3.

Table 3: Properties of geo-foam (Abdi and Zandieh, 2014).

\begin{tabular}{|c|c|c|c|c|c|c|c|}
\hline $\begin{array}{c}\text { Unit } \\
\text { weight } \\
\left(\mathrm{Kn} / \mathrm{m}^{3}\right)\end{array}$ & $\begin{array}{c}\text { Elasticity } \\
\text { modulus } \\
(\mathrm{E}) \\
\left(\mathrm{Kn} / \mathrm{m}^{2}\right)\end{array}$ & $\begin{array}{c}\text { Cohesion } \\
(\mathrm{c}) \\
\left(\mathrm{Kn} / \mathrm{m}^{2}\right)\end{array}$ & $\begin{array}{c}\text { Dilation } \\
\text { angle }\end{array}$ & $\begin{array}{c}\text { Angle } \\
\text { of } \\
\text { friction }\end{array}$ & $\begin{array}{c}\text { Poisson's } \\
\text { ratio }\end{array}$ & $\begin{array}{c}\text { Interaction } \\
\text { coefficient } \\
\text { for } \\
\text { transverse } \\
\text { member } \\
\left(\mathrm{R}_{\text {inter }}\right)\end{array}$ & $\begin{array}{c}\text { Material } \\
\text { model }\end{array}$ \\
\hline 0.181 & 1960 & 50 & 0 & 0.01 & 0.098 & 1 & Mohr -coulomb \\
\hline
\end{tabular}

\subsection{Interface strength}

Interface is modelled by virtual thickness interface element which is calculated as "virtual thickness factor times the average element size" .Interaction coefficient, $\mathrm{R}\left(R_{\text {inter }}\right.$, in case of Plaxis v8.6) is defined as the ratio of the shear strength at soil structure interface (Vermeer and Brinkgreve, 1995).

$$
\tan (\delta)=R \tan (\varphi)
$$


Where, $\delta$ is the skin friction angle (interaction friction angle) between soil and reinforcement; $\mathrm{R}$ is the interaction coefficient and $\varphi$ is the angle of soil friction. Vermeer and Brinkgreve (1995), Khedkar and Mandal (2009), Abdi and Zandieh (2014) have proposed the following equation for equivalent depth $\left(d_{e q}\right)$ :

$$
d_{e q}=\sqrt{12 \frac{E I}{E A}}
$$

Where, EI is flexural rigidity of member and EA is the axial stiffness. To simulate the stiffness of transverse members, equivalent depth (equivalent thickness) of these members $\left(d_{e q}\right)$ was specified as 2, 7, $15 \mathrm{~mm}$ in three categories geogrid in this paper. Interference between transverse members is an important factor affecting grid behaviour and is a function of length, thickness and spacing of these elements (Palmeira, 1987; Palmeira and Milligan, 1989; Abdi and Zandieh, 2014).

\subsection{Geometrical Modelling}

To simulate pull-out test, geometry of the box has been modelled similar to that of actual test box as shown in Fig.3 has been used by Abdi and Zandieh (2014). Bottom boundary was modelled by total fixity, whereas normal boundary was fixed horizontally, so that soil could not move horizontally beyond the boundary, yet settlement of soil was permitted. Normal pressure was modelled by uniformly distributed load on top surface of soil and pull-out load simulated as horizontal nodal force. Longitudinal members of reinforcement were modelled by geogrid element and transverse members by plate elements as stiffness is the important parameter for these members (Khedkar and Mandal, 2009; Abdi and Zandieh, 2014).Length of box was $100 \mathrm{~cm}$, height and width of $60 \mathrm{~cm}$ was designed and fabricated.

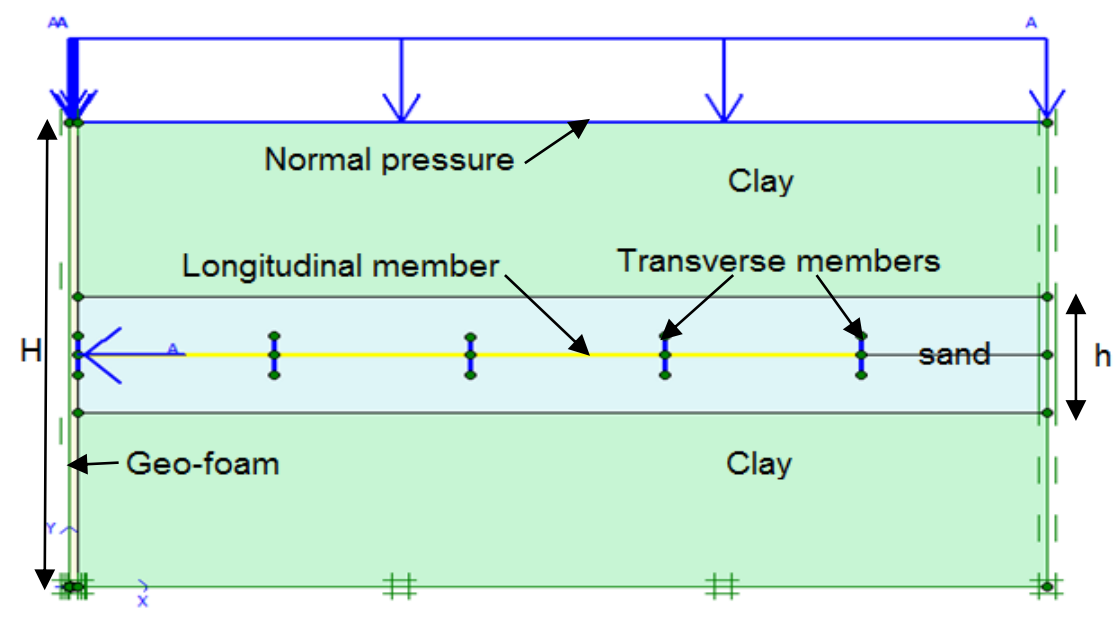

Fig. 3: Geometrical model using for pull-out test.

\subsection{Verify numerical simulation}

In order to verify the numerical simulation, pull-out test conducted by Abdi and Zandieh (2014) have been simulated. For comparative purpose, results of numerical analysis and experimental and experimental test for claysand-geogrid samples as pull-out force versus sand layer thickness encapsulating the geogrid in Fig. 4. Numerical and experimental results show good agreement. The differences vary maximum of $15 \%$. 


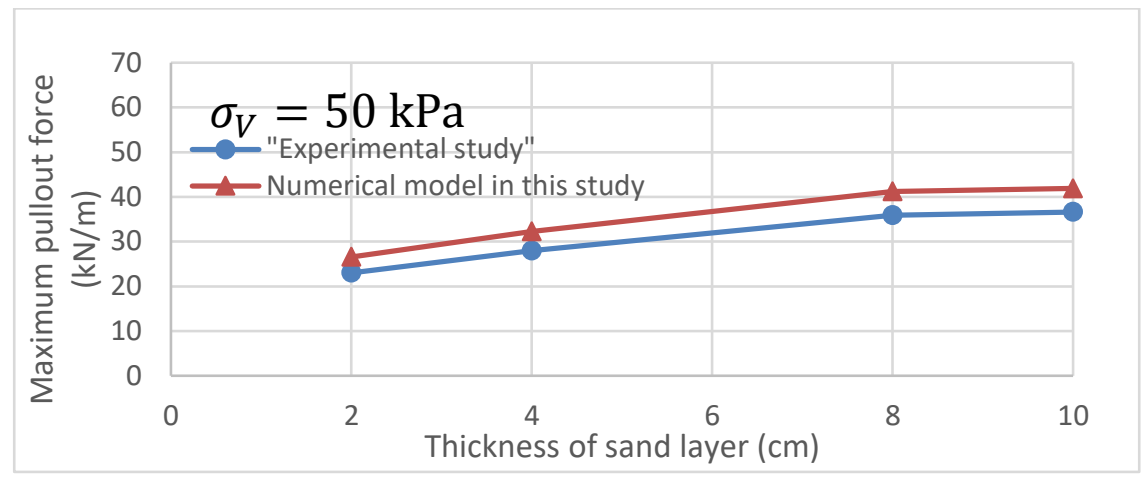

Fig. 4: Comparison between numerical and experimental results.

\section{Results}

Finite element method has been used for modelling pull-out test while the soil were sand and clay, reinforcement embedded in thin layers of sand.

\subsection{Influence categories of geogrid on pull-out force}

Results illustrate difference between pull-out resistance in three category of geogrids is minimal when the length of geogrids are $25 \mathrm{~cm}$ and $50 \mathrm{~cm}$ but in $75 \mathrm{~cm}$ and $97 \mathrm{~cm}$ lengths of geogrid pull-out resistance in welded straps is greater than other categories. In enhancement due to increasing axial stiffness (EA) and decrease mesh size than from two category of geogrids. Fig. 5(a)-(c) show Variations of maximum pull-out force versus length of geogrid in three category of geogrids.

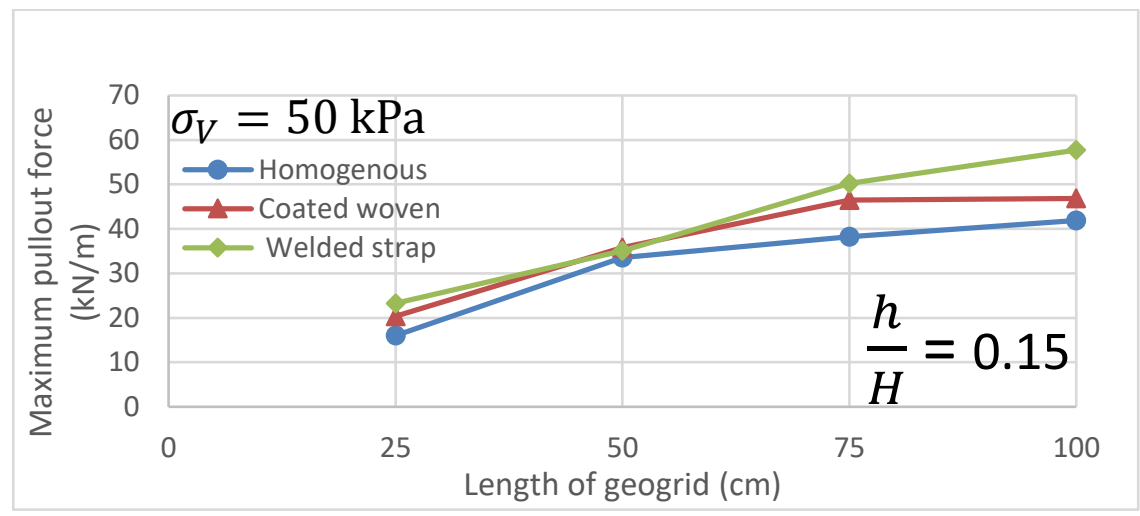

(a) Variations of maximum pull-out force versus length of geogrid in three category of geogrids.

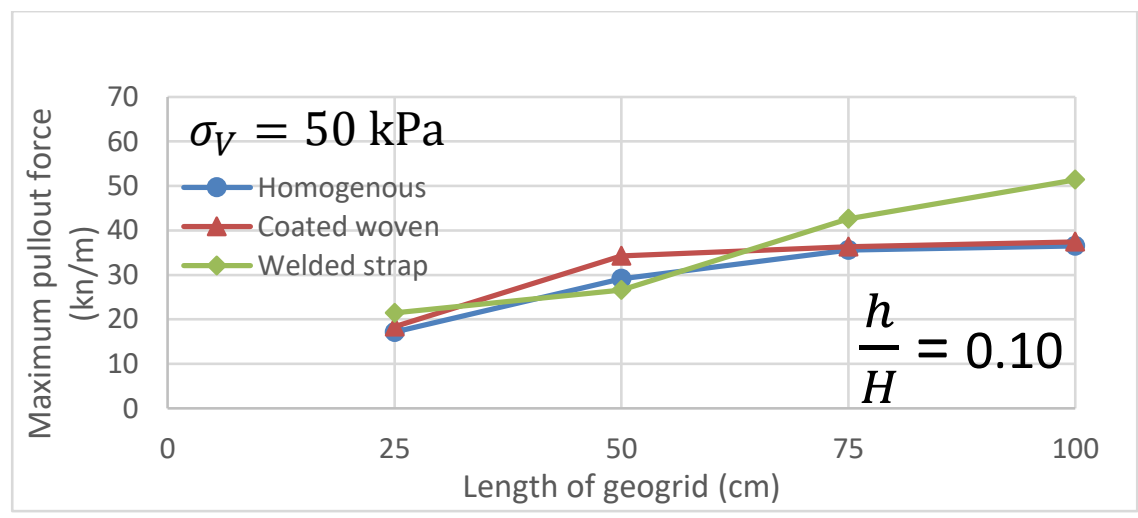

(b) Variations of maximum pull-out force versus length of geogrid in three category of geogrids. 


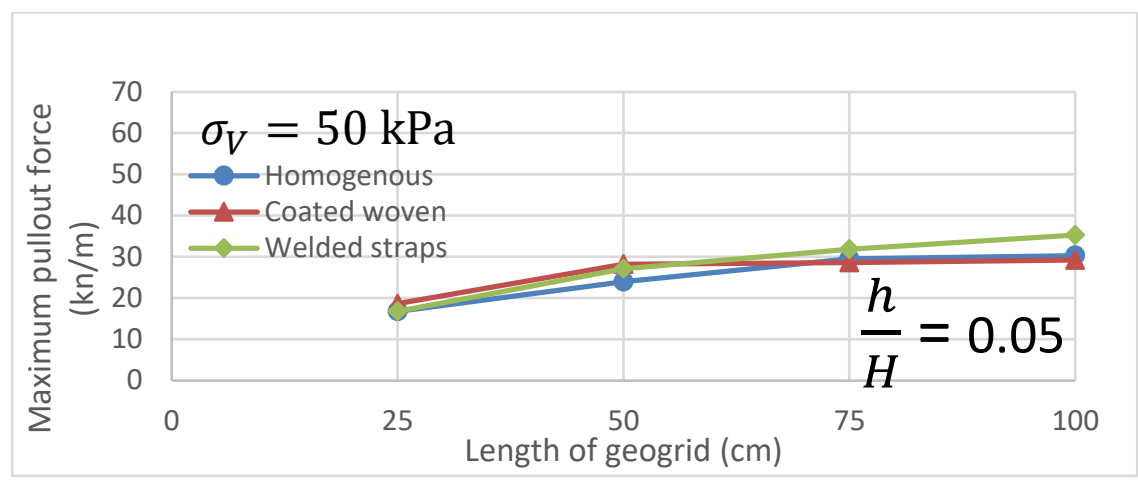

(c) Variations of maximum pull-out force versus length of geogrid in three category of geogrids.

Fig. 5: Variations of maximum pull-out force versus length of geogrid in three category of geogrids.

\subsection{Influence sand layer around the reinforcement}

Fig. 6(a)-(c) show variation of pull-out force versus length of geogrids. Based on these observation, pull-out resistance increase by increase ratio of thickness sand layer to test box height. The enhancement of pull-out resistance is mainly due to the passive soil resistance building up in front of transverse members until a state of failure is reached in the soil close to the reinforcement. The proportion of passive soil resistance in front of trans- verse members is considerably larger than the friction resistance along the geogrid and the overall restraint provided is determined by particle size and grading of the soil also reported by Palmeira (2009), Touahamia et al. (2002) and Abdi and Zandieh (2014).

Maximum pull-out force obtained for $\frac{h}{H}=0.15$ and $97 \mathrm{~cm}$ length of geogrid were approximately 41.9, 46.84 and $57.72 \mathrm{kN} / \mathrm{m}$ at Homogenous, Coated woven and Welded straps respectively. This is a clear indication that the provision of thin sand layers around reinforcements in clayey soils increase pull-out resistance even to the level as if the whole sample had comprised of granular materials. Using this method would make it possible to use inferior low quality materials as backfill in soil structures (Abdi and Zandieh, 2014). According to the results thickness of sand layers to the text box height ratio of 0.15 has been found as optimum.

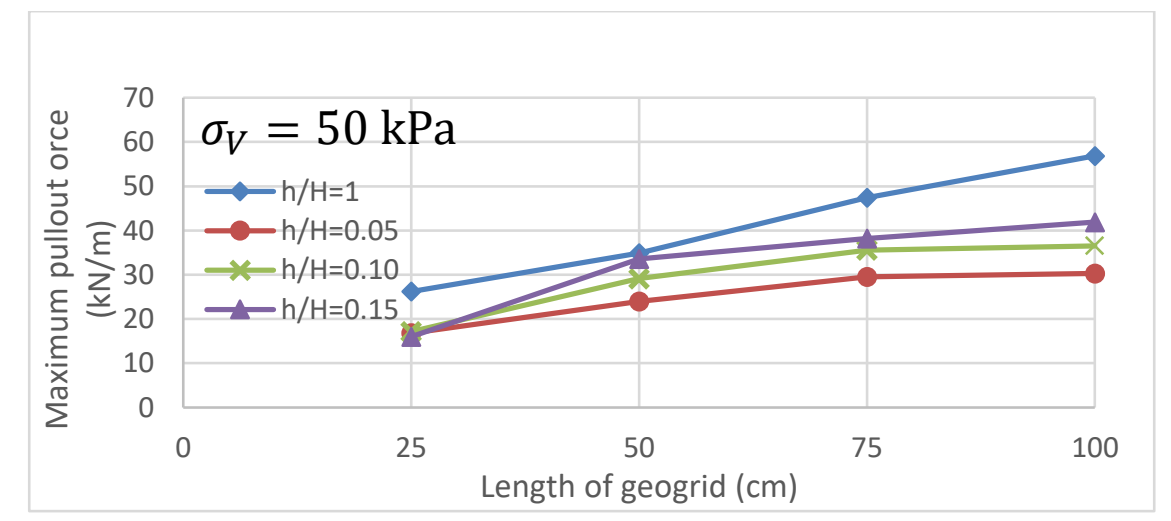

(a) Variations of maximum pull-out force versus length of geogrid in Homogenous Category. 


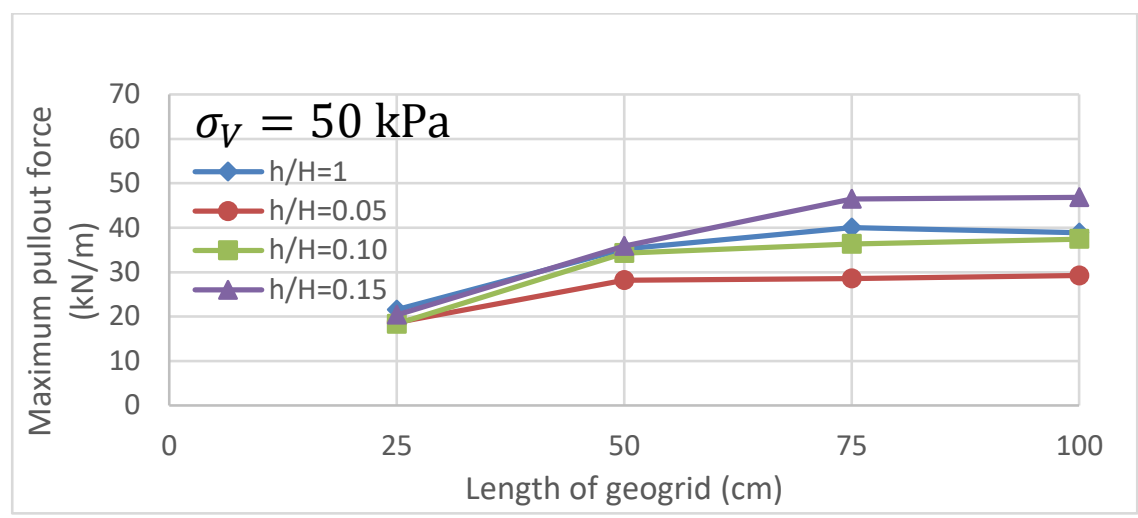

(b) Variations of maximum pull-out force versus length of geogrid in Coated woven Category.

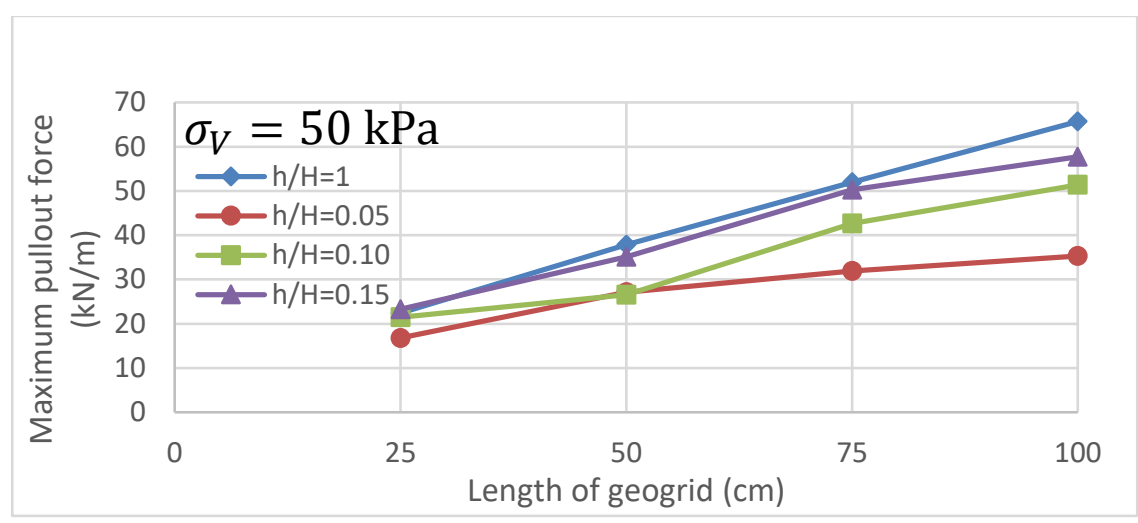

(c) Variations of maximum pull-out force versus length of geogrid in Welded straps Category.

Fig. 6: Variations of maximum pull-out force versus length of geogrid in three categories of geogrids.

\subsection{Influence Length of geogrid}

In order to study effect length of geogrid, investigation employing a finite element program has been conducted to simulate pull-out test. Analysis was carried out using a normal pressure of $50 \mathrm{kPa}$, geogrid length 25, 50, 75 and $97 \mathrm{~cm}$ and ratios of thickness sand layer to test box height $\left(\frac{h}{H}\right)$ were $0.05,0.10$ and 0.15 .

In all cases, pull-out force increased by increasing length of geogrid. The rate of increase pull-out forces in all categories of geogrids due to decrease mean stress distribution between successive transvers members by increasing length of geogrids from $25 \mathrm{~cm}$ to $75 \mathrm{~cm}$ is greater than from $75 \mathrm{~cm}$ to $97 \mathrm{~cm}$. Fig. 7 shows simulation numerical results, while ratio was 0.15 .

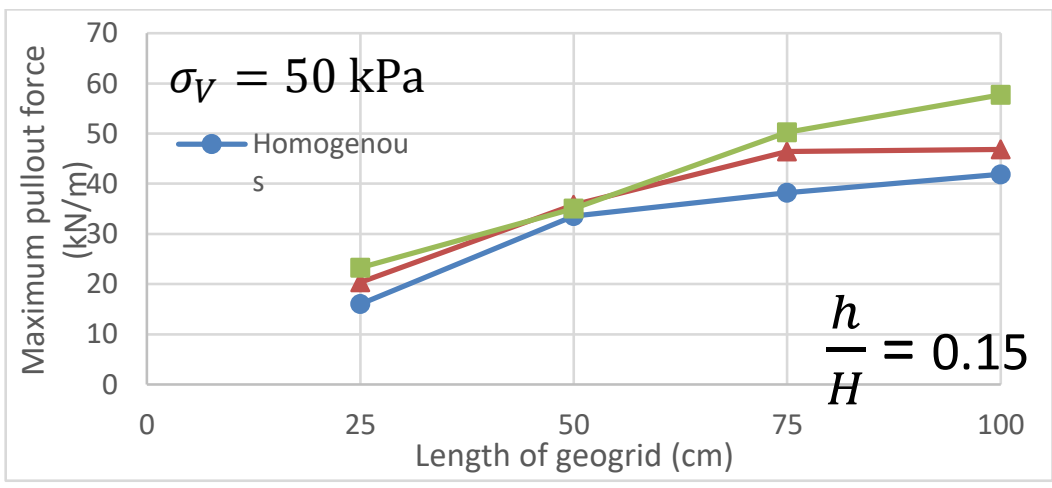

Fig. 7: Variations as of maximum pull-out force versus length of geogrid. 


\section{Conclusion}

The pull-out test has been simulated for evaluating the interaction of clays reinforced with three category geogrids encapsulated in thin layers of sand for promoting the use of inferior soils in soil structures. Based on the numerical results, the following conclusions have been drawn:

- Encapsulation of geogrids with thin sand layer increased pull-out force in clay reinforced structures. Maximum pullout force obtained for $\frac{h}{H}=0.15$ and $97 \mathrm{~cm}$ length of geogrid was approximately $57.72 \mathrm{kN} / \mathrm{m}$ at Welded straps respectively

- Maximum pull-out force has been obtained in Welded straps category. This type of geogrid has a axial stiffness greater than the other two category of geogrids.

- Pull-out force increased by increasing length of geogrid. The rate of increase in pull-out forces by increasing length of geogrids from $25 \mathrm{~cm}$ to $75 \mathrm{~cm}$ is greater than from $75 \mathrm{~cm}$ to $97 \mathrm{~cm}$.

\section{References}

[1] M. R. Abdi, A. Sadrnejad, M. A. Arjomand, "Strength enhancement of clay by encapsulating geogrids in thin layers of sand," Geotext. Geomembr., vol. 27, no. 6, 447e455, 2009.

[2] M. R. Abdi, M. Arjomand, "Pull-out tests conducted on clay reinforced with geogrid encapsulated in thin layers of sand," Geotext. Geomembr., vol. 29, no. 6, 588e595, 2011.

[3] S. H. Lajevardi, D. Dias, J. Racines, "Analysis of soil-welded steel mesh reinforcement interface interaction by pullout tests," Geotextiles and Geomembranes, vol. 40, Pages 48-57, 2013.

[4] S. H. Lajevardi, L. Briançon, D. Dias, "Experimental studies of the geosynthetic anchorage effect of geometric parameters and efficiency of anchorages," Geotextiles and Geomembranes, vol. 42, no. 5, pp. 505-514, 2014.

[5] M. S. Khedkar, J. N. Mandal, "Pull-out behavior of cellular reinforcements," Geotext. Geomembr., vol. 3, no. 1, 262e271, 2009.

[6] R. J. Bathurst, T. M. Allen, D. L. Walters, "Reinforcement loads in geosynthetic wall and the case for a new working stress design method," Geotext. Geomembr., vol. 23, no. 4, 287e322, 2005.

[7] D. T. Bergado, J. C. Chai, H. O. Abiera, M. C. Alfaro, A.S. Balasubramaniam, "Interaction between cohesivefrictional soil and various grid reinforcements," Geotext. Geomembr., vol. 12, no. 4, 327e349, 1993.

[8] E. M. Palmeira, "The Study of Soil-reinforcement Interaction by Means of Large Scale Laboratory Test," Ph.D. thesis, Magalen College, University of Oxford, England, 1987.

[9] E. M. Palmeira, G. W. E. Milligan, "Scale and other factors affecting the results of pull-out tests of grid buried in sand," Geotechnique, vol. 11, no. 3, 511e524, 1989.

[10] E. M. Palmeira, "Bearing force mobilization in pull-out tests on geogrids," Geotext. Geomembr., vol. 22, no. 6, 481e509, 2004.

[11] E. M. Palmeira, "Soil-geosynthetic interaction," Geotext. Geomembr., vol. 27, no. 5, 368e390, 2009.

[12] S. H. C. Teixeira, B. S. Bueno, J.G., Zornberg, "Pull-out force of individual longitudinal and transverse geogrid ribs," J. Geotech. Geoenviron. Eng., vol. 133, no. 1, 37e50, 2007.

[13] M. R. Abdi, A. R. Zandieh, "Experimental and numerical analysis of large scale pull-out tests conducted on clays reinforced with geogrids encapsulated with coarse material," Geotext. Geomembr., vol. 42, no. 5, 494e504, 2014.

[14] D. T. Bergado, J.-C. Chai, "Pull-out force/displacement relationship of extensible grid reinforcements," Geotext. Geomembr., vol. 13, no. 5, 295e316, 1994.

[15] J. Esfandiari, M. R. Selamat, "Laboratory investigation on the effect of transverse member on pull-out capacity of metal strip reinforcement in sand," Geotext. Geomembr., vol. 35, 41e49, 2012.

[16] N. Moraci, G. Cardile, "Influence of cyclic tensile loading on pull-out resistance of geogrids embedded in a compacted granular soil," Geotext. Geomembr., vol. 27, no. 6, 475e487, 2009.

[17] N. Moraci, G. Cardile, "Deformative behaviour of different geogrids embedded in a granular soil under monotonic and cyclic pull-out loads," Geotext. Geomembr., vol. 32, 104e110, 2012.

[18] M. Mosallanezhad, S. S. Taghavi, N. Hataf, M. Alfaro, "Experimental and numerical studies of the performance of the new reinforcement system under pull-out conditions," Geotext. Geomembr., vol. 44, no. 1, 70e80, 2016.

[19] I. Yogarajah, K. C. Yeo, "Finite element modelling of pull-out tests with load and strain measurements," Geotext. Geomembr., vol. 13, no. 1, 43e54, 1994. 
[21] P. A. Vermeer, R. B. J. Brinkgreve, "Finite Element Code for Soil and Rock Analysis," A.A. Balkema, Rotterdam (Netherlands), 1995.

[22] R. M. Koerner. An Overview of Geogrids, Symposium of polymer geogrid reinforcement, 2009, Available: http://www.tensar.co.uk/jubilee-symposium/downloads.html 